\title{
Der Kongress OSTEOLOGIE 2019 in Frankfurt am Main
}

Der Jahreskongress des Dachverbandes Osteologie (DVO) e. V. fand in diesem Jahr in der Mainmetropole Frankfurt statt. Vom 28.-30.03.2019 luden die Kongresspräsidenten Prof. Dr. med. Andreas Kurth (Koblenz) und Prof. Dr. med. Peyman Hadji (Frankfurt am Main) unter dem Motto „Healthy Aging - Bone and Joint“" zum wissenschaftlichen Austausch.

Die vielfältigen Themen der Osteologie, die wieder durch viele Innovationen und wissenschaftliche Erkenntnisse getragen wurden, standen im Mittelpunkt des Kongresses. Neben den klassischen Themen der Osteologie wurden den rund 1100 Teilnehmern auch Sessions zu besonderen Fragestellungen wie Arthrose, Wirbelsäulenerkrankungen, Hormonersatztherapie, Kinderosteologie und Osteoonkologie angeboten und damit ein breites Informationsspektrum - von Grundlagen über Diagnostik bis zur Therapie - rund um die Veränderungen des Bewegungsapparates geboten, um damit „Healthy Aging - Bone and Joint“ in der täglichen Praxis umzusetzen.

\section{Die Location}
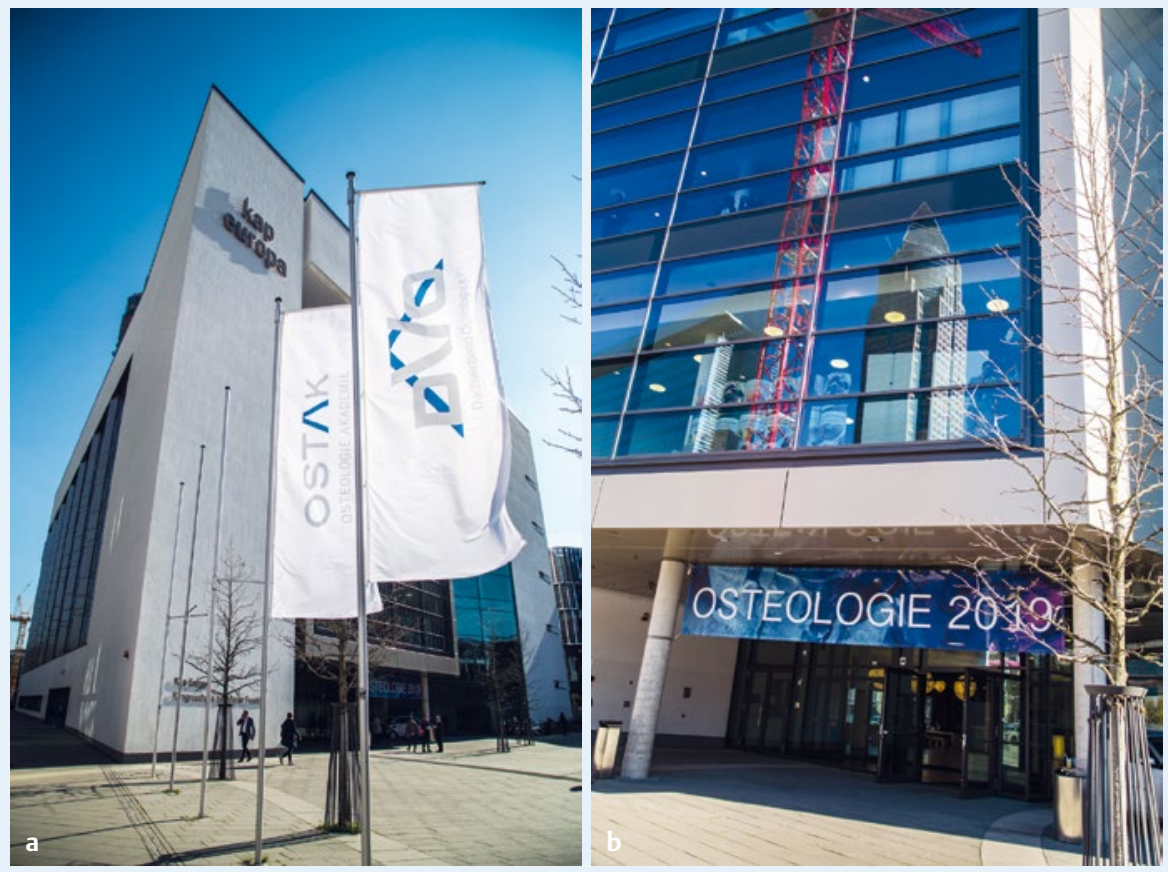

- Abb. 1 Die OSTEOLOGIE 2019 fand im modernen und nachhaltig konzipierten Kongresshaus Kap Europa der Messe Frankfurt statt. Große bodentiefe Fensterfronten und hohe Decken sorgten für eine einzigartige Kulisse.

\section{Wissenschaftlicher Austausch}
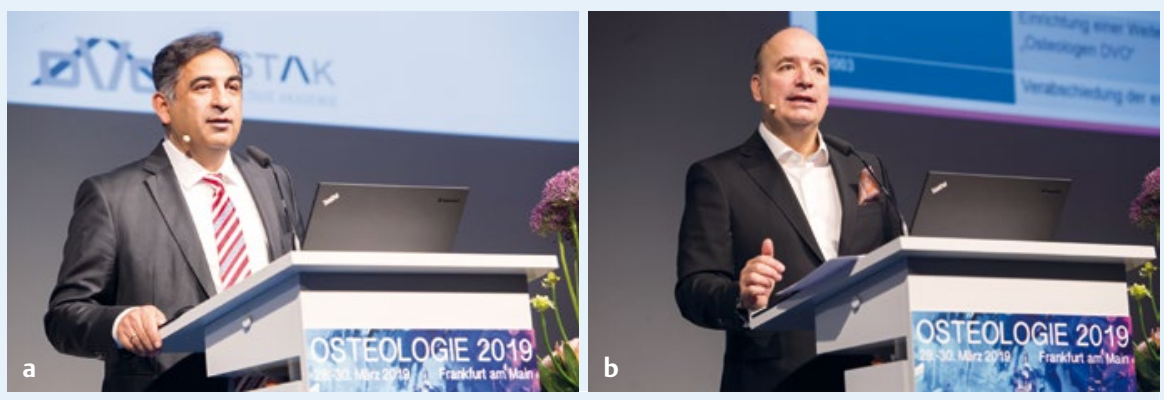

- Abb. 2 Die Kongresspräsidenten Prof. Dr. med. Peyman Hadji (Frankfurt am Main) (a) und Prof. Dr. med. Andreas Kurth (Koblenz) (b) brachten sich aktiv ins Programm ein und hielten viele innovative Vorträge. 

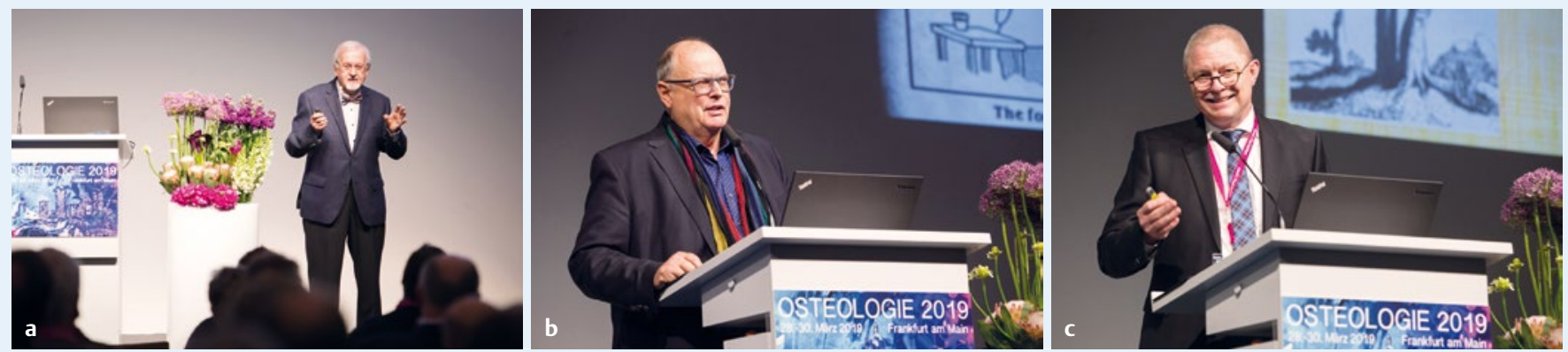

- Abb. 3 Das Highlight des Kongresses war der Festvortrag zum Thema „Healthy Aging im Spiegel der Zeit“ - aufgeteilt in die drei Themen „Geschichte der Osteologie“ durch Doz. Dr. sc. med. Klaus Abendroth (Jena) (a), „Geschichte der Onkologie“ durch Prof. Dr. med. Ingo Diel (Mannheim) (b) und „Geschichte der Orthopädie“ durch Prof. Dr. med. Michael Rauschmann (Offenbach) (c).

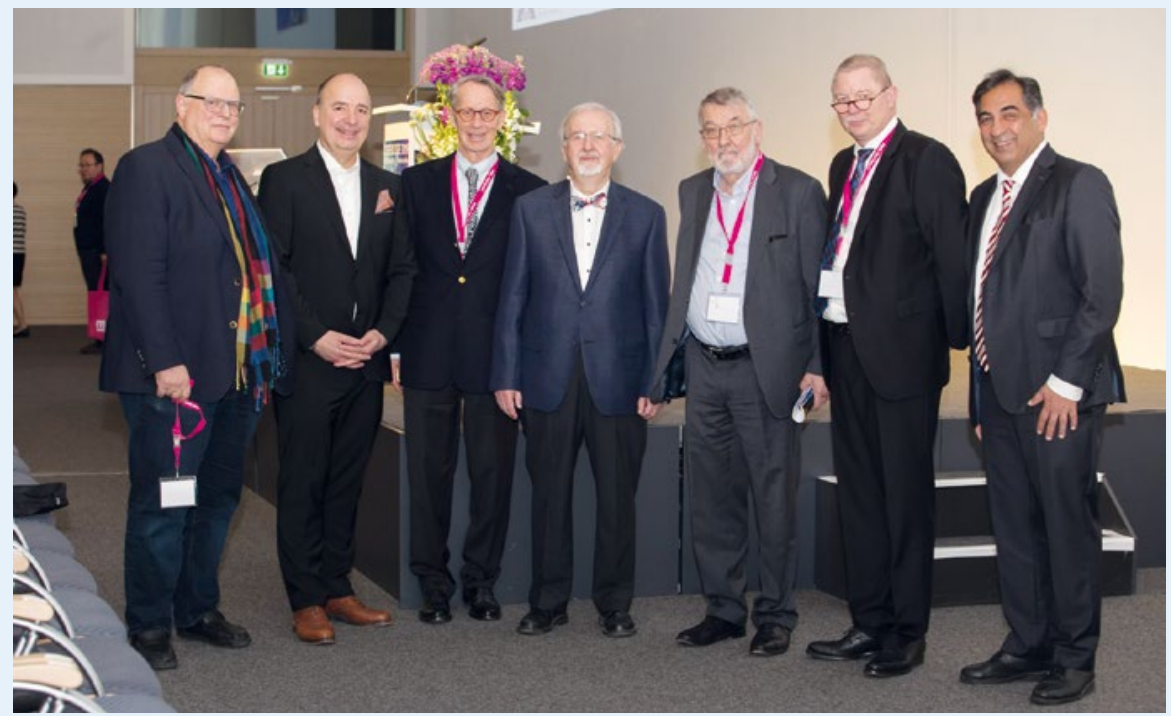

Abb. 4 Die Kongresspräsidenten dankten den Rednern und Vorsitzenden des Festvortrages. Von links: Prof. Dr. med. Ingo Diel (Mannheim), Prof. Dr. med. Andreas Kurth (Koblenz), Prof. Dr. med. Johann Diederich Ringe (Leverkusen), Doz. Dr. sc. med. Klaus Abendroth (Jena), Prof. Dr. med. Helmut Minne (Halberstadt), Prof. Dr. med. Michael Rauschmann (Offenbach) und Prof. Dr. med. Peyman Hadji (Frankfurt am Main).

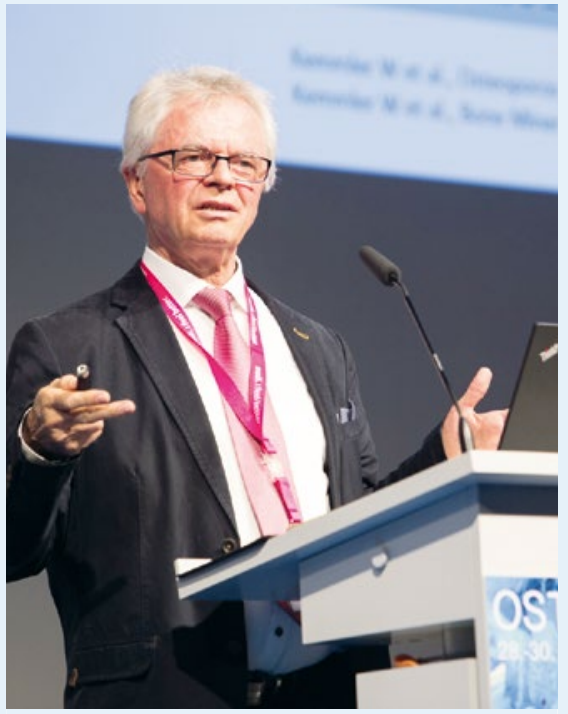

Abb. 5 In Anerkennung seiner herausragenden wissenschaftlichen Leistungen hielt Prof. Dr. med. Franz Jakob (Würzburg) einen der Hauptvorträge des Kongresses - die Uehlinger Lecture der DGO.
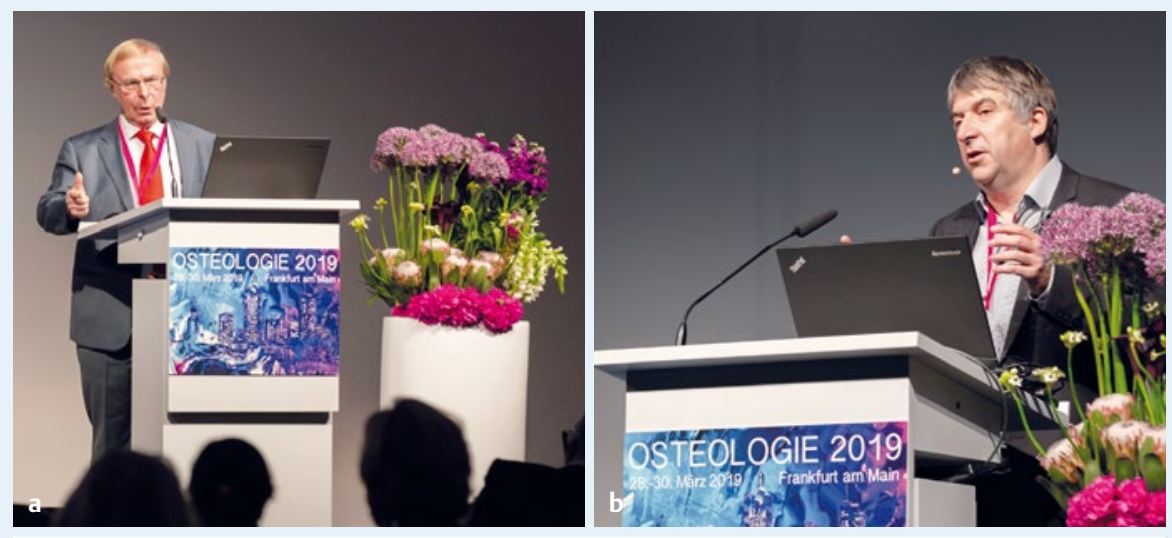

- Abb. 6 Am Samstag stand im Hauptsaal alles unter dem Motto HRT. Namhafte Experten, wie Prof. Dr. med. Alfred O. Muck (Tübingen, Beijing) (a) oder Prof. Thomas Römer (Köln) (b) referierten zum Thema Hormonersatztherapie. 

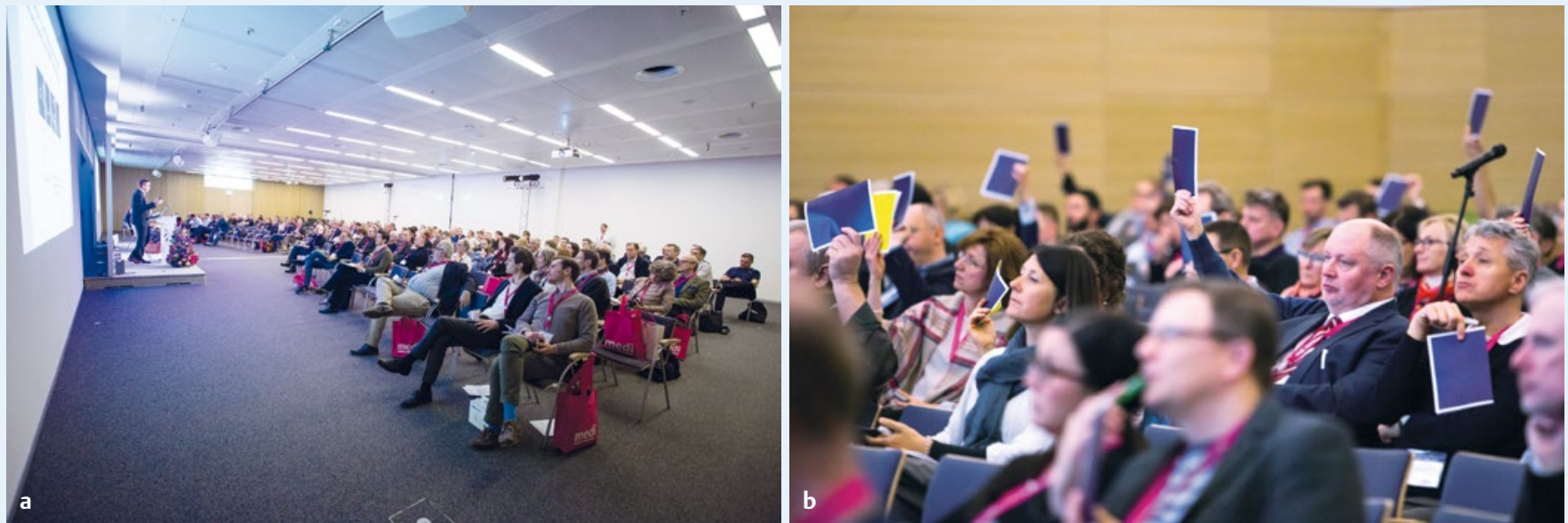

- Abb. 7 a, b Interessierte Teilnehmer, beliebte Vorträge und interdisziplinäre Sessions bildeten einen runden Rahmen für den wissenschaftlichen Austausch.

\section{Nachwuchsförderung im Fokus - Die Preisträger der OSTEOLOGIE 2019}

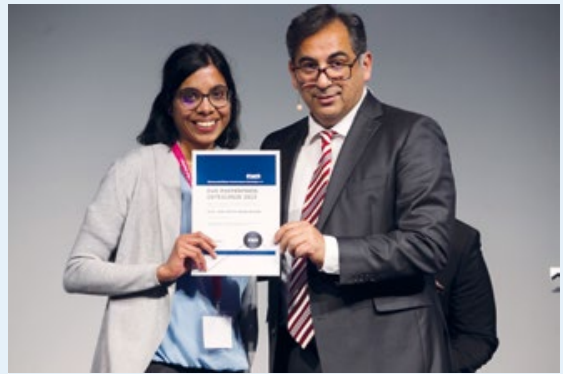

Abb. 8 Janina Vavanikunnel (Basel) erhielt einen DVO-Posterpreis für das Thema „Association between gkycaemic control and fracture risk in diabetic patients: a nested case control study“.

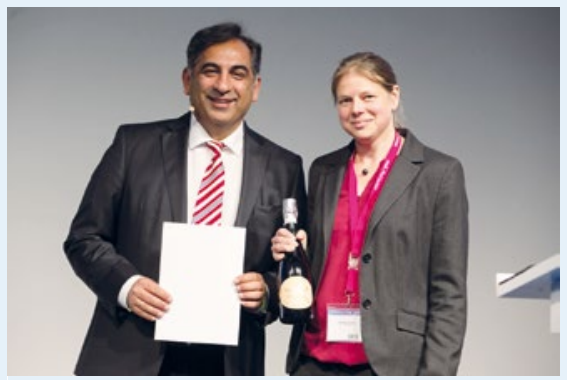

- Abb. 9 Marietta Hermann (Würzburg) nahm den DVO-Posterpreis für das Thema „Evaluation of Preclinical Models for Testing of Bone Engineered Constructs Need for Optimization“ entgegen.

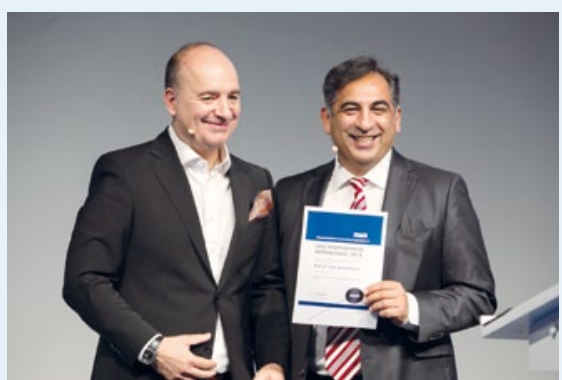

Abb. 10 Überraschung beim Kongresspräsidenten: Die Jury prämierte auch das Poster von Prof. Dr. med. Andreas Kurth (Koblenz) zum Thema „TRAP 5b as an early predictor for implant loosening in a rat model“ mit einem Posterpreis des DVO.

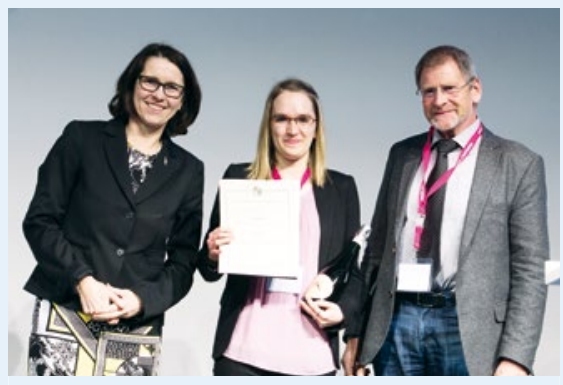

Abb. 11 Einen DGO-Posterpreis erhielt Anne Marie Ecke (Senftenberg) für das Poster zum Thema „Agar overlay technique vs. v-buttom plate: differentiation of human cartilage-like microtissues depend on plate format". Die zweite Posterpreisträgerin der DGO war Daniela Kildal (UIm) für das Poster „Dicke des Palatinum durum im CT - ein diagnostisches Kriterium zur Erkennung einer Osteoporose“.

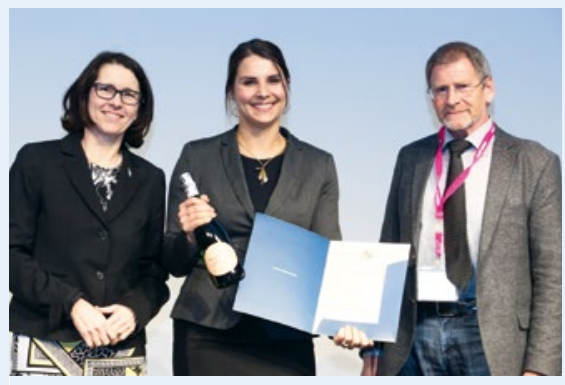

Abb. 12 Dr. med. Franka Genest (Würzburg) erhielt ein Reisestipendium der DGO für den besten Vortrag im Forum Junge Wissenschaft. 


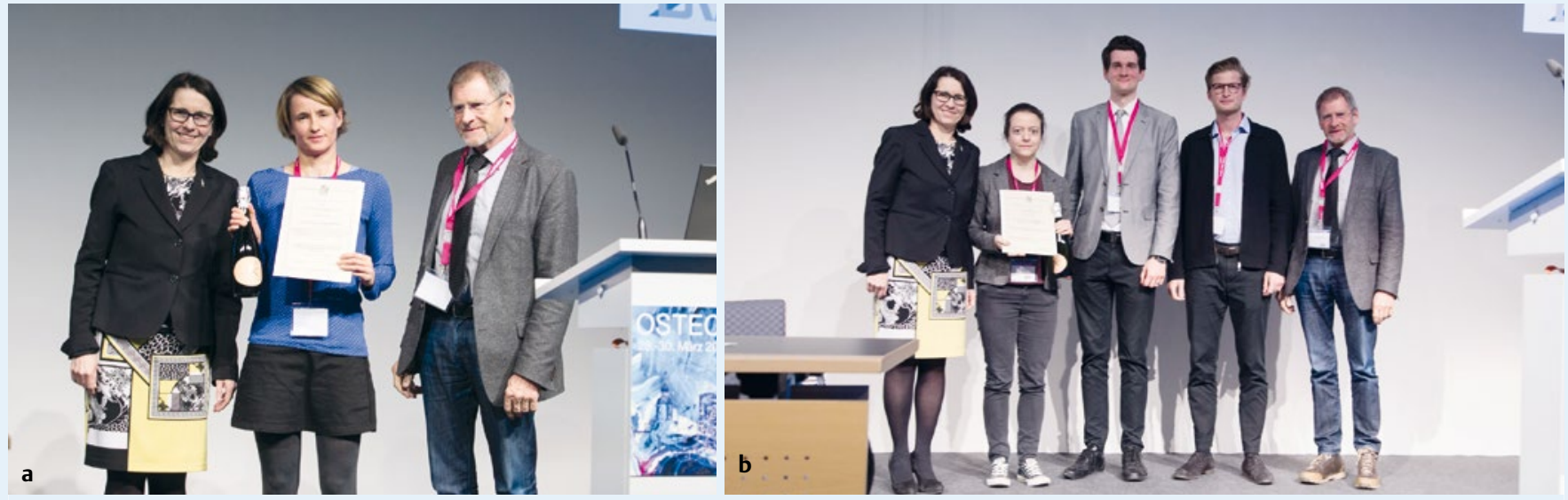

- Abb. 13 Der Copp-Preis der DGO hatte in diesem Jahr 2 Preisträger. Zum einen verliehen die Präsidentin der DGO Frau Prof. Dr. med. Heide Siggelkow (Göttingen) und der Vizepräsident Herr Prof. Dr. med. Hans Christof Schober (Rostock) den Preis an Frau Dr. rer. nat Ulrike Baschant (Dresden) für das Thema „Transferrin receptor 2 controls bone mass and pathological bone formation via BMP and Wnt signaling“ (a). Zum anderen ging der Copp-Preis an die Gruppe um Dr. rer. nat. Julia Luther (Hamburg), Dr. rer.nat. Timur Alexander Yorgan (Hamburg) und Dr. med. Tim Rolvien (Hamburg) für Ihre Forschungsergebnisse zum Thema „Wnt1 is an Lrp5-independant bone-anabolic Wnt-ligand“ (b).

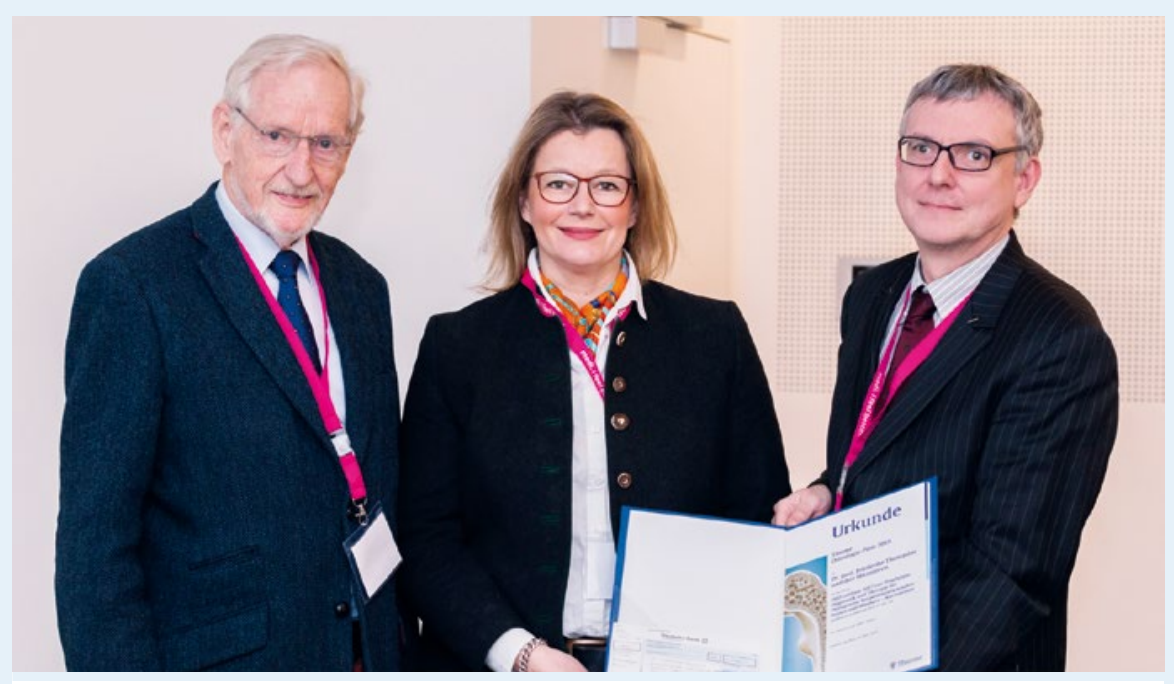

- Abb. 14 Den Thieme Osteologie-Preis 2019 für den besten Artikel des Jahres 2018 erhielt Frau Dr. med. Friederike Thomasius (Frankfurt am Main).

\section{Der Knochen zieht weiter}

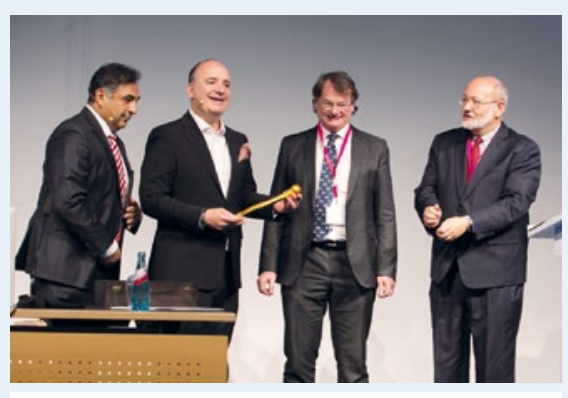

Abb. 15 Feierlich wurde der Kongressknochen an die Kongresspräsidenten der OSTEOLOGIE 2020 überreicht.

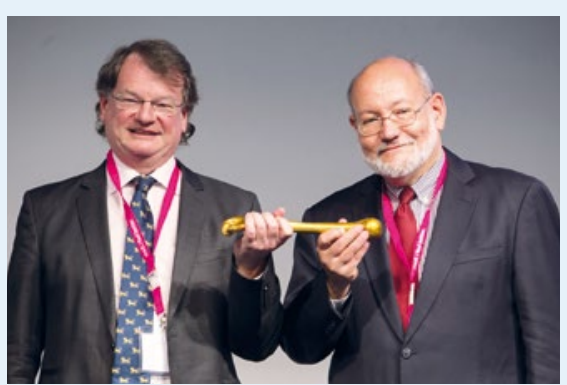

Abb. 16 PD Dr. med. habil. Stephan Scharla (Bad Reichenhall) und Prim. Dr. med. Peter Bernecker (Wien) freuen sich auf die Vorbereitungen für die OSTEOLOGIE 2020. 